\title{
Dual Mechanism for Type-2 Diabetes Resolution after Roux-en-Y Gastric Bypass
}

EDWARD LIN, D.O., S. SCOTT DAVIS, M.D., JAHNAVI SRINIVASAN, M.D.,* JOHN F. SWEENEY, M.D.,* THOMAS R. ZIEGLER, M.D.,+ LAWRENCE PHILlIPS, M.D., NANA GLETSU-MILLER, Ph.D.*

From the Departments of *Surgery and +Medicine, Emory Bariatrics, Atlanta, Georgia

\begin{abstract}
Resolution of Type-2 diabetes mellitus (DM) after weight loss surgery is well documented, but the mechanism is elusive. We evaluated the glucose-insulin metabolism of patients undergoing a Roux-en-Y gastric bypass (RYGB) using the intravenous glucose tolerance test (IVGTT) and compared it with patients who underwent laparoscopic adjustable gastric band (AB) placement. Thirty-one female patients (age range, 20 to 50 years; body mass index, $47.2 \mathrm{~kg} / \mathrm{m}^{2}$ ) underwent RYGB. Nine female patients underwent $A B$ placement and served as control subjects. All patients underwent IVGTT at baseline and 1 month and 6 months after surgery. Thirteen patients undergoing RYGB and one patient undergoing $A B$ exhibited impaired glucose tolerance defined by the American Diabetes Association. By 6 months post surgery, diabetes was resolved in all but one patient undergoing RYGB and none of the patients undergoing AB. Patients with diabetes undergoing demonstrated increased insulin secretion and $\beta$-cell responsiveness 1 month after surgery and continued this trend up to 6 months, whereas none of the patients undergoing $A B$ had changes in $\beta$-cell function. Both patients undergoing RYGB and those undergoing $A B$ demonstrated significant weight loss $\left(34.6\right.$ and $35.0 \mathrm{~kg} / \mathrm{m}^{2}$, respectively) and improved insulin sensitivity at 6 months. RYGB ameliorates DM resolution in two phases: 1) early augmentation of beta cell function at 1 month; and 2) attenuation of peripheral insulin resistance at 6 months. Patients undergoing $A B$ only exhibited reduction in peripheral insulin resistance at 6 months but no changes in insulin secretion.
\end{abstract}

$\mathrm{R}$ ESOLUTION OF TYPE-2 diabetes mellitus (T2DM) after weight loss surgery has been well documented with gastric bypass operations, ${ }^{1-3}$ but there is evidence that the restrictive adjustable band procedure also promotes T2DM resolution. ${ }^{4}$ The mechanisms of diabetes resolution are presumably different between a malabsorptive operation such as the Roux-en-Y gastric bypass (RYGB) and the restrictive adjustable gastric band $(\mathrm{AB})$. The drastically distinct surgical approaches to weight loss surgery aiming to achieve the same benchmark of T2DM resolution beg the question of which operation is most appropriate for a morbidly obese patient with dysfunction of insulin-glucose metabolism.

\footnotetext{
Presented at the Annual Scientific Meeting and Postgraduate Course Program, Southeastern Surgical Congress, Atlanta, GA, February 7-10, 2009.

This study is funded in part by National Institutes of Health/ National Institute of Diabetes and Digestive and Kidney Diseases R03 DK067167 (NGM) and National Institutes of Health/ACTSI Grant M01 RR00039.

Address correspondence and reprint requests to Edward Lin, D.O., Department of Surgery, Emory University School of Medicine, 1364 Clifton Road (H124), Atlanta, GA 30322. E-mail: Elin2@emory.edu.
}

If both procedures are eventually equal in efficacy, the mere cost and surgical risk reduction of the simpler procedure would clearly be the best choice, and yet there are data that the mere diversion of food from the proximal gastrointestinal tract (eg, biliopancreatic diversion, RYGB) offers profound and almost immediate relief (less than 1 month) from T2DM..$^{5-7}$

In this study, we used a standardized intravenous glucose tolerance test (IVGTT) to determine the baseline characteristics and subsequent response of insulinglucose metabolism in morbidly obese patients with T2DM undergoing either RYGB or the AB. We hypothesize that RYGB induces alterations in pancreatic $\beta$-cell function, which is not observed with the $A B$ procedure. Knowing this information may help patients and surgeons determine which procedures are most appropriate for them based on their baseline phenotype.

\section{Methods}

\section{Patients and Inclusion Criteria}

Women between the ages of 18 and 50 years were recruited into the study with ongoing treatment for T2DM and $\mathrm{HgA}_{1} \mathrm{C}$ greater than 6 per cent. The choice 
of surgery was a decision between the patients and their surgeons, but patients generally presented after having decided on their preferred procedure based on completely psychosocial rationale (eg, risk fear, acquaintance with the same surgery, permanent foreign body, complexity of procedure). Exclusion criteria were male, age younger than 18 or older than 50 years, body mass index (BMI) less than $35 \mathrm{~kg} / \mathrm{m}^{2}$, and current smoking history.

\section{Study Protocol}

The study has had 6 years of continuous approval by the Institutional Review Board of Emory University, and metabolic evaluations were all conducted in the Atlanta Clinical and Translational Studies Institute (CTSI, formerly the General Clinical Research Center of Emory University). Patients admitted to the CTSI had the following measurements: IVGTT, anthropometry, and adipose tissue distribution. All measurements were obtained at baseline (0 months) and 1, 6, and 24 months after surgery. However, for the purposes of this study, the acute changes of interest were only within the first 6 months after surgery because very little metabolic change was anticipated at 24 months. Subjects were weight-stable $( \pm 1 \mathrm{~kg})$ for 1 week before each measurement time point, with the exception of 1 month in which significant weight loss occurs (approximately $3 \mathrm{~kg} /$ week). Medications were withheld on the morning of the glucose tolerance testing.

\section{Intravenous Glucose Tolerance Test, $\beta$-Cell Function, Insulin Sensitivity}

Insulin action was assessed using the frequently sampled IVGTT. Patients were admitted to the CTSI the night before testing and fasted overnight (12 hours). Intravenous access was established for blood sampling, and the study began as previously described. ${ }^{8}$ A standard approach using minimal modeling analysis ${ }^{9}$ (MinMod Millennium, Los Angeles, CA) of glucose and insulin levels was used to quantify insulin sensitivity ( $\mathrm{Si}$, a measure of peripheral resistance), acute insulin response to glucose (AIRg, a measure of $\beta$-cell function and insulin secretion), and disposition index $(\mathrm{DI}=\mathrm{Si} \times \mathrm{AIRg})$, a quantitative measurement that describes the dynamic relationship between $\beta$-cell responsiveness and insulin sensitivity. In metabolically normal individuals, changes in insulin sensitivity are accompanied by compensatory alterations in the $\beta$ cell's sensitivity to glucose. Patients with T2DM typically have lower DI than normal individuals. Patient hemoglobin $\mathrm{A}_{1} \mathrm{C}\left(\mathrm{HgA}_{1} \mathrm{C}\right)$ was also measured for the purposes of this study.

\section{Surgical Procedures}

RYGB were performed laparoscopically in all patients. In brief, a 20 - to $30-\mathrm{mL}$ gastric pouch is formed in a longitudinal fashion. The Roux limb is typically 100 to $150 \mathrm{~cm}$ in length. Patients undergoing B patients had the Lap-Band system (Allergan Inc., Irvine, CA) with the first band fill 4 to 6 weeks after surgery with the aid of fluoroscopy and contrast esophagram to rapidly achieve optimal restriction.

\section{Statistical Analysis}

Analysis was performed using STATISTICA (StatSoft, Tulsa, OK). Differences between time points were analyzed using paired Student $t$ test. Significance is $P<0.05$, and results are expressed as mean \pm SEM.

\section{Results}

\section{Patient Characteristics}

Patients who had RYGB had greater BMIs than those who underwent $A B$ (47.2 vs $44.2 \mathrm{~kg} / \mathrm{m}^{2}$, respectively) at baseline. At 6 months postsurgery, RYGB subjects and $A B$ subjects exhibited the same trend in weight loss, but the patients undergoing RYGB had more precipitous weight reduction in the same time period than patients undergoing $\mathrm{AB}$. By 6 months, both patients undergoing RYGB and those undergoing $\mathrm{AB}$ had similar BMIs (34.6 vs $35.0 \mathrm{~kg} / \mathrm{m}^{2}$ ) (Fig. 1).

\section{Diabetes Resolution}

Thirty-one patients had RYGB and nine had AB. Of these patients, 13 patients undergoing RYGB and one

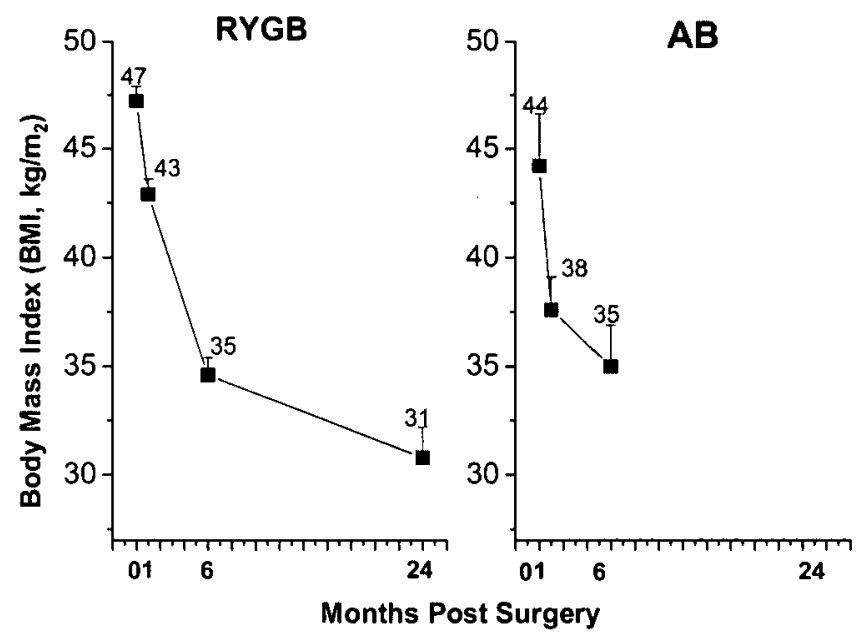

FiG. 1. Changes in body mass index (BMI) at 6 months after Roux-en-Y gastric bypass (RYGB) and the adjustable gastric band $(A B)$. Weight changes are no different between the two surgical groups, but significantly different at each time point for the individual surgery $(P<0.05)$. 
undergoing $\mathrm{AB}$ had impaired glucose tolerance or frank diabetes as defined by the American Diabetes Association. By 6 months postsurgery, diabetes was resolved in all but one patient who had undergone RYGB and none of the patients who had undergone $A B$.

\section{Insulin Sensitivity}

In the nondiabetic subjects, peripheral insulin sensitivity was similar in both RYGB and $\mathrm{AB}$ subjects, but both were lower than normal-weight control subjects $(1.90 \pm 0.3$ and $1.36 \pm 0.21$ vs $2.50 \mathrm{Si}$ units in normalweight control subjects, $P<0.05$ ). Insulin sensitivity was normalized in both nondiabetic RYGB and $A B$ groups at 6 months after surgery $(3.02 \pm 0.43$ and $3.13 \pm$ $0.85 \mathrm{Si}$ units, respectively, $P=$ not significant).

In RYGB subjects with prediabetes and diabetes, insulin sensitivity was also lower than normal-weight control subjects $(2.04 \pm 0.29$ vs $2.50 \mathrm{Si}$ units). Only one patient undergoing $\mathrm{AB}$ had diabetes with very low insulin sensitivity $(0.11 \mathrm{Si}$ units) at baseline. At 6 months, both surgical groups with diabetes had significant improvements in insulin sensitivity (RYGB $2.04 \pm 0.29$ vs $3.38 \pm 0.51, \mathrm{AB} 0.11$ to $5.46 \mathrm{Si}$ units).

\section{Insulin Secretion}

At baseline, nondiabetic RYGB subjects had much greater insulin secretion compared with those who were diabetic $(672 \pm 93$ vs $30 \pm 17$ AIRg units, $P<$ $0.005)$. Similarly, nondiabetic AB subjects had greater insulin secretion compared with the one $\mathrm{AB}$ subject who had diabetes $(1011 \pm 189$ vs -33 AIRg units).

After surgery, nondiabetic patients undergoing RYGB had a slight elevation in insulin secretion, but then dropped below baseline 6 months postsurgery (400 \pm 42 AIRg units, $P<0.05$ compared with baseline). For both diabetic and nondiabetic patients undergoing $\mathrm{AB}$, insulin secretion exhibited minimal to no change after surgery. In contrast, there was a pronounced surge in insulin secretion in patients with diabetes undergoing RYGB at 1 and 6 months (from $30 \pm 25$ at baseline to $110 \pm 54$ and $155 \pm 38$ AIR units at 1 month and 6 months, respectively, $P<0.05$ ).

$\beta$-cell function measured by the DI was impaired at baseline in subjects with prediabetes and diabetes compared with those with normal glucose tolerance. Subjects with diabetes who underwent RYGB experienced immediate improvements in $\beta$-cell function (from $61 \pm$ 5 at baseline to $431 \pm 45$ and $703 \pm 27$ at 1 month and 6 months postsurgery, respectively, $P<0.05$ ) (Table 1 ).

\section{Discussion}

It is widely accepted that T2DM is a combination of dysfunctional insulin secretion by $\beta$-cells and insulin sensitivity (peripheral resistance) that results in impaired glucose homeostasis. Indeed, it is possible that a patient with T2DM possesses very robust $\beta$-cell function to compensate for impaired peripheral resistance or has combined attenuations in $\beta$-cell function and insulin sensitivity. Unfortunately, most patients with T2DM presenting for weight loss surgery have no information on the phenotype they possess.

In this study, we observed that patients with T2DM undergoing RYGB exhibit and early restoration of pancreatic $\beta$-cell function measured by AIRg at 1 month. There is a second phase of improved insulin-glucose metabolism as exhibited by profound improvements in peripheral Si at 6 months, which also led to an improved DI. However, although the amount of weight loss after $A B$ was similar to $R Y G B$, there is never an improvement observed in AIRg in patients undergoing $\mathrm{AB}$, but only a modest improvement in insulin sensitivity at 6 months, which is presumably from weight loss.

Data for normoglycemic patients undergoing both weight loss procedures were also presented to give context to the data observed in patients with diabetes. Although it is beyond the scope of this discussion, it is readily evident that morbidly obese patients without diabetes probably maintain normoglycemia by highoutput insulin secretion, and once peripheral insulin sensitivity improves after weight loss, insulin secretion is reduced below baseline levels. Although there was only one patient with diabetes who had $A B$, the data found in normoglycemic patients undergoing $A B$ demonstrate that this procedure has virtually no effect on $\beta$-cell function. These data are also novel in that there are no reports to our knowledge using IVGTT to follow patients undergoing $\mathrm{AB}$ for weight loss.

It is not clear how the RYGB augments $\beta$-cell function so soon after surgery, but several plausible explanations have been proposed. Several experimental studies have shown that ghrelin inhibits insulin release in mice, rats, and humans. ${ }^{10} \mathrm{We}$ and others have shown early decreases in the "hunger" hormone ghrelin after gastric bypass. " Blockade of ghrelin signaling markedly increase glucose-induced insulin release in vitro. In high-fat diet-induced mildly obese mice, ghrelin deficiency enhances insulin release and prevents impaired glucose tolerance. ${ }^{12}$ If these observations are validated, it is potentially feasible to manipulate ghrelin signaling as a treatment for T2DM.

Another plausible and popular explanation is that the intestinal rearrangement sending nutrients rapidly to the distal small bowel induces a significant rise in GLP-1. ${ }^{13}$ Other investigators administering GLP-1 intravenously demonstrated a dose-dependent rise in insulin secretion as well. ${ }^{14}$ Insulin secretion by the $\beta$ cell undoubtedly occurs by multiple hormone stimuli and the mechanisms are incompletely understood. 
TABLE 1. Changes in Insulin Sensitivity (Si), Insulin Secretion (AIRg), and B-cell Function (DI) at Baseline, I Month, and 6 Months after Weight Loss Surgery

\begin{tabular}{|c|c|c|c|c|}
\hline & \multicolumn{4}{|c|}{ Before Surgery } \\
\hline & GBP & GBP & $\mathrm{AB}$ & $A B$ \\
\hline & $\begin{array}{l}\text { Nondiabetes } \\
(n=18)\end{array}$ & $\begin{array}{l}\text { Prediabetes } \\
\text { and Diabetes } \\
(\mathrm{n}=13)\end{array}$ & $\begin{array}{l}\text { Nondiabetes } \\
\quad(\mathrm{n}=8)\end{array}$ & $\begin{array}{l}\text { Prediabetes and Diabetes } \\
\qquad(n=1)\end{array}$ \\
\hline \multirow[t]{4}{*}{$\begin{array}{l}\text { Si units } \\
\text { AIRg units } \\
\beta \text {-cell function (DI units) }\end{array}$} & $\begin{aligned} 1.90 & \pm 0.30 \\
672 & \pm 93 \\
1,276 & \pm 28\end{aligned}$ & $\begin{array}{c}2.04 \pm 0.29 \\
30 \pm 17^{*} \\
61 \pm 5^{*}\end{array}$ & $\begin{array}{l}1.36 \pm 0.21 \\
1,011 \pm 189 \\
1,375 \pm 40\end{array}$ & $\begin{array}{c}0.11 \\
-33(0) \\
0\end{array}$ \\
\hline & \multicolumn{4}{|c|}{1 Month Postsurgery } \\
\hline & GBP & GBP & $\mathrm{AB}$ & $\mathrm{AB}$ \\
\hline & $\begin{array}{l}\text { Nondiabetes } \\
(\mathrm{n}=15)\end{array}$ & $\begin{array}{l}\text { Prediabetes and Diabetes } \\
\qquad(\mathrm{n}=11)\end{array}$ & $\begin{array}{l}\text { Nondiabetes } \\
(\mathrm{n}=6)\end{array}$ & $\begin{array}{l}\text { Prediabetes and Diabetes } \\
\qquad(\mathrm{n}=1)\end{array}$ \\
\hline \multirow[t]{4}{*}{$\begin{array}{l}\text { Si units } \\
\text { AlRg units } \\
\beta \text {-cell Function (DI units) }\end{array}$} & $\begin{aligned} 1.70 & \pm 0.32 \\
793 & \pm 194 \\
1,348 & \pm 62\end{aligned}$ & $\begin{array}{l}2.76 \pm 0.89 \\
156 \pm 51 \dagger \\
431 \pm 45 \dagger\end{array}$ & $\begin{aligned} 1.32 & \pm 0.20 \\
911 & \pm 178 \\
1,203 & \pm 36\end{aligned}$ & $\begin{array}{l}\text { Not determined } \\
\text { Not determined } \\
\text { Not determined }\end{array}$ \\
\hline & \multicolumn{4}{|c|}{6 Months Postsurgery } \\
\hline & GBP & GBP & $\mathrm{AB}$ & $\mathrm{AB}$ \\
\hline & $\begin{array}{l}\text { Nondiabetes } \\
(\mathrm{n}=18)\end{array}$ & $\begin{array}{l}\text { Prediabetes and diabetes } \\
\qquad(\mathrm{n}=10)\end{array}$ & $\begin{array}{l}\text { Nondiabetes } \\
\quad(\mathrm{n}=5)\end{array}$ & $\begin{array}{l}\text { Prediabetes and diabetes } \\
\qquad(\mathrm{n}=1)\end{array}$ \\
\hline $\begin{array}{l}\text { Si units } \\
\text { AIRg units } \\
\beta \text {-cell Function (DI units) }\end{array}$ & $\begin{aligned} 3.02 & \pm 0.43 \\
400 & \pm 42 \\
1,200 & \pm 18\end{aligned}$ & $\begin{array}{l}3.38 \pm 0.51 \\
208 \pm 53 t \\
703 \pm 27 t\end{array}$ & $\begin{aligned} 3.13 & \pm 0.85 \\
861 & \pm 207 \\
2,695 & \pm 176\end{aligned}$ & $\begin{array}{l}5.46 \\
2 \\
11\end{array}$ \\
\hline
\end{tabular}

* Significantly different from nondiabetes, $P<0.05$.

* Significantly different from nondiabetes, $P<0.05$.

There is also molecular explanation for the reversal of peripheral insulin resistance after weight loss. ${ }^{15}$ Bikman and colleagues demonstrated how muscles become desensitized to insulin transport by inappropriate phosphorylation of the subcellular insulinreceptor substrate-I (by the inhibitor of kappa B kinase $\beta$, which commonly accumulates with high adipose volumes.

In summary, this study showed that weight loss between the patients undergoing $A B$ and those undergoing RYGB follow the same early trends, but RYGB clearly induces an acute insulin response from $\beta$-cells early postoperatively, whereas $A B$ does not. With this information, it is possible that patients with T2DM with intact or robust $\beta$-cell function should be offered a restrictive operation such as the sleeve gastrectomy or an adjustable gastric band as a way to increase insulin sensitivity and thereby increase the DI. In patients with attenuated $\beta$-cell function, gastric bypass may offer the more expeditious route to T2DM reversal. In essence, the decision to choose a restrictive procedure or a combined restrictive-malabsorptive procedure can potentially be made based on a patient's insulin secretion and peripheral resistance profile. Although such a concept is ideal, there are other complementary biomarkers that predict resolution of T2DM such as inflammatory mediators ${ }^{16}$ and adiponectin. ${ }^{17}$ Therefore, the ability to predict a patient's response from weight loss surgery and choosing the ideal treatment will most likely rely on an aggregate of related physiological profiles rather than independent parameters.

\section{REFERENCES}

1. Torquati A, Lufti R, Abumrad N, Richards WO. Is Roux-en$Y$ gastric bypass surgery the most effective treatment for type 2 diabetes mellitus in morbidly obese patients? J Gastrointest Surg 2005;9:1112-8.

2. Schauer PR, Burguera B', Ikramuddin S, et al. Effect of laparoscopic Roux-en-Y gastric bypass on type-2 diabetes mellitus. Ann Surg 2003;238:467-85.

3. Laferrère B, Teixeira J, McGinty J, et al. Effect of weight loss by gastric bypass surgery versus hypocaloric diet on glucose and incretin levels in patients with type 2 diabetes. J Clin Endocrinol Metab 2008;93:2479-85.

4. Dixon JB, O'Brien PE, Playfair J, et al. Adjustable gastric banding and conventional therapy for type 2 diabetes: a randomized controlled trial. JAMA 2008;299:316-23. 
5. DePaula AL, Macedo ALV, Rassi N, et al. Laparoscopic treatment of metabolic syndrome in patients with type 2 diabetes mellitus. Surg Endosc 2008;22:2670-8.

6. Cummings DE, Overduin J. Gastrointestinal regulation of food intake. J Clin Invest 2007;117:13-23.

7. Strader AD, Calusen TR, Goodin SZ, Wendt D. Ileal interposition improves glucose tolerance in low dose streptozotocintreated diabetic and euglycemic rats. Obes Surg 2009;19:96-104.

8. Miller NG, Hansen JM, Jones DP, et al. Loss of total and visceral adipose tissue mass predicts decreases in oxidative stress after weight-loss surgery. Obesity (Silver Spring) 2009;17:439-46.

9. Matthews DR, Hosker JP, Rudenski AS, et al. Homeostasis model assessment: insulin resistance and $\beta$-cell function from fasting plasma glucose and insulin concentrations in man. Diabetologia 1985;28:412-9.

10. Dezaki K, Sone H, Yada T. Ghrelin is a physiological regulator of insulin release in pancreatic islets and glucose homeostasis. Pharmacol Ther 2008;1 18:239-49.

11. Lin E, Gletsu N, Fugate K, et al. The effects of gastric division on systemic ghrelin concentrations in the morbidly obese. Arch Surg 2003;124:754-61.

\section{DISCUSSION}

STEPHAN S. MCNATT, M.D. (Winston-Salem, NC; Opening Discussion): In this study, Dr. Lin and his group from Emory University shed more light on what has been a mysteriously pleasant effect of bariatric surgery. Because obesity and Type- 2 diabetes are epidemic in our culture, this research into how operations, as old as RYGB and as new as laparoscopic adjustable gastric banding, real work is timely and in some respects overdue. Dr. Lin and his group used a simple test, the IVGTT, in an elegant manner to discern changes in insulin resistance and $\beta$-cell function in patients undergoing RYGB and laparoscopic AB. Their work lends more credence to the "foregut hypothesis," as promoted by Rubino and others, as a mechanism for the acute resolution of Type- 2 diabetes in patients undergoing RYGB. In other words, bypassing the duodenum and proximal jejunum leads to improved $\beta$-cell function and glucose homeostasis by an as yet incompletely recognized mediator or pathway. In addition, weight loss itself leads to decreased peripheral insulin resistance and a consequent improvement in Type-2 diabetes through a different mechanism.

The lack of patients with diabetes in the laparoscopic adjustable gastric band group is concerning. Why was there only one patient in the band group with diabetes? Would your study not have been strengthened by having more data on patients with diabetes in this group? Would you agree that it is difficult to make any meaningful observation about the acute insulin response to glucose in patients with diabetes in the band group given that there was only one such patient in the study? If, as you conclude, adjustable gastric banding leads to improvements in insulin resistance only, it would have been nice to see this in your data.

For both RYGB and AB, the resolution of diabetes occurs at a rate of 80 per cent in the best of circumstances (ie, in those who have had the disease for less than 5 years). Two patients in your study, one in each group, did not see
12. Dezaki K, Sone H, Koizumi M, et al. Blockade of pancreatic islet-derived ghrelin enhances insulin secretion to prevent highfat diet-induced glucose intolerance. Diabetes 2006;55:3486-93.

13. Bose M, Oliván B, Teixeira J, et al. Do incretins play a role in the remission of type 2 diabetes after gastric bypass surgery: what are the evidence. Obes Surg 2009;19:217-29.

14. Kjems LL, Holst JJ, Volund A, Madsbad S. The influence of GLP-1 on glucose-stimulated insulin secretion: effects on beta-cell sensitivity in type 2 and nondiabetic subjects. Diabetes 2003;52: 380-6.

15. Bikman BT, Zheng D, Pories WJ, et al. Mechanism for improved insulin sensitivity after gastric bypass surgery. J Clin Endocrinol Metab 2008;93:4656-63.

16. Gletsu N, Lin E, Khaitan L, et al. Changes in C-reactive protein predict insulin sensitivity in severely obese individuals after weight loss surgery. J Gastrointest Surg 2005;9:111928.

17. Lin E, Phillips LS, Ziegler TR, et al. Increases in adiponectin predict improved liver, but not peripheral, insulin sensitivity in severely obese women during weight loss. Diabetes 2007;56: $735-42$.

resolution of their diabetes. Do you see the length of time with Type-2 diabetes as being a potential confounding variable for its resolution and was this accounted for in your study? Are improvements in insulin resistance and $\beta$-cell function after RYGB or $A B$ independent of the length of time that a patient has had Type- 2 diabetes?

Should we be testing all of our bariatric surgery candidates with glucose tolerance tests and obtaining measures of $\beta$-cell function and peripheral insulin resistance?

Do you foresee a tailoring of bariatric procedures based on a patient's comorbid conditions?

EUGENE SHIVELY, M.D. (Campbellsville, KY): Is gastric bypass going to become a treatment for diabetes? If so, what BMI are you going to choose and which patients would we send to the bariatric surgeon?

LEENA KHAITAN, M.D. (Chardon, OH): Should we test the insulin secretion in all of our patients? Sometimes they will ask us whether they should have a band or bypass. Should we test them preoperatively when we are discussing the procedures with the patients?

KIRBY BLAND, M.D. (Birmingham, AL): Could you give us a little more insight into to what you suggest the shutdown mechanism is physiologically from the proximal or distal duodenum and jejunum? Is there a feedback loop as to why you shutdown insulin production? That seems like the physiological consequences. People are doing the banding because it is a much simpler operation and you do not have to do a formal anastomosis.

PAUL WHITLOCK, M.D. (Statesboro, GA): My understanding is that most people who have a band lose approximately 100 pounds and then stabilize. What would be the recurrence rate of diabetes after they stabilize?

EDWARD LIN, D.O. (Atlanta, GA; Closing Discussion): We had only one patient undergo lap band surgery who had diabetes, so there is some bias. The gastric bypass data have been somewhat evolving over the last 5 years for this group. When a patient with diabetes comes in and tells me that they 
want the $\mathrm{AB}$ procedure, I educate them. If they then want the band, we will do it. It does not really dilute the data in the patients undergoing gastric bypass versus the patients undergoing banding. In the patients undergoing gastric bypass, the insulin secretion definitely goes up when you do the IVGTT at I month. Even with the patients with a normal band, we do not see that.

The two patients who did not resolve their diabetes were young patients younger than 40 years old, and we do not know why.

We do not believe one operation fits all. We used to think sleeve gastrectomy operations were a simple restrictive operation, but we are finding that these patients, when given a meal challenge test, get dumping syndrome, and their diabetes goes away. We are finding different hormones change with this operation. There is probably more than just one operation for everyone. There are three efficacious operations out there. Safety is definitely an issue. The safest operation is a restrictive operation. The Roux-en- $Y$ bypass would go to the back of the line.

Is diabetes treated by Roux-en-Y bypass? What BMI is appropriate? The Centers for Medicare and Medicaid Services disapproved that concept this year, because there were not enough data. Data from Asia and Brazil on smaller patients with a BMI of $30 \mathrm{~kg} / \mathrm{m}^{2}$ and Type- 2 diabetes suggests improvement. If a patient has a BMI of $32 \mathrm{~kg} / \mathrm{m}^{2}$, is diabetic, and can pay for the operation; I would not keep it from them.

Should we test all of our patients? That would be ideal. If we are serious about curing diabetes, we really need to know the mechanism of the diabetes. Patients may be low insulin secretors or have high peripheral insulin resistance. There are patients who are both, and they do not do well.

What is the mechanism of shutting down the insulin? That is the million dollar question. There is a burnout factor. There is a point where insulin production will be really high to compensate for the peripheral resistance, but after awhile, it burns out.

In our patients with diabetes who had the Roux-en-Y and lost the excess weight, none had their diabetes recur. With the patients undergoing banding, we have seen some have to go back on oral medications. All you have to do is lose 40 to 45 pounds to gain the benefit of Type- 2 diabetes resolution. You have very little wiggle room when you do not lose that much weight. If you lose 150 pounds with the Roux-en-Y and you gain back 30 pounds, then you are still way ahead of the game. My bias with the band is that if you only lose 60 pounds and you gain back 30 , then that gives you a smaller area to maintain that diabetes resolution. 
Copyright of American Surgeon is the property of Southeastern Surgical Congress and its content may not be copied or emailed to multiple sites or posted to a listserv without the copyright holder's express written permission. However, users may print, download, or email articles for individual use. 